\title{
EFFECTS OF LASER IRRADIATION ON ADHESIVE TRIBO-PERFORMANCE OF EVA/HDPE/MA-G-PE/OMMT BLENDED POLYMER NANOCOMPOSITES
}

DOI : 10.36909/jer.ICIPPSD.15517

\author{
R. Namdeo*, S. Tiwari**, S. Manepatil ${ }^{* *}$ \\ *Department of Mechanical Engineering, Shri Vaishnav Polytechnic College, Indore- India \\ ** Department of Mechanical Engineering, Shri G.S. Institute of Technology \& Science, Indore, \\ India \\ *Email: rrnamdeo@ rediffmail.com; Corresponding Author.
}

\begin{abstract}
Ethylene-co-vinyl acetate (EVA), high density polyethylene (HDPE) and their blends are being used in many engineering applications. In this work, an attempt was made to extend the conventional uses of EVA/HDPE blended polymer nanocomposites by laser treating their surface to automobile, aircraft, and similar industries, where tribological properties played an important role. Effects of laser irradiation on adhesive tribo-performances of maleic anhydride grafted polyethylene (MA-g-PE: 2phr) modified ethylene-co-vinyl acetate/high density polyethylene (EVA/HDPE: 70/30 wt. \%) organ modified montmorillonite (OMMT: 4phr) blended polymer nanocomposite have been investigated. EVA/HDPE/MA-g-PE/OMMT polymer nanocomposite was irradiated by Ytterbium laser system (YSL-2000) at various scan speeds and power densities. As per ASTM G99 standard, tribo-performance attributes coefficient of friction and specific wear rate were evaluated using pin-on-disc machine against rotating EN31 steel disc of $60 \mathrm{HRC}$ at different loads and speeds. Wear mechanisms of worn surfaces were analyzed using scanning electron microscopy (SEM) images. It was observed that coefficient of friction and specific wear rate were significantly affected by power density and load, while sliding distance and scan speed have marginal effects.
\end{abstract}

Key words: EVA/HDPE/MA-g-PE/OMMT Polymer Nanocomposites; Laser irradiation; Adhesive wear; Coefficient of friction; SEM. 


\section{INTRODUCTION}

High development costs for new polymers initiated the development of polymer blends in which dilution of high-cost polymers at low-cost polymers takes place with desirable properties. Polymer blend is an alloy of at least two polymers, which are blended to create a new material with tailored properties (Robeson.,1984). Specific wear rate of high molecular weight polyethylene (UHMWPE) and polytetrafluoroethylene blend under dry sliding friction was decreased by 2 times in contrast with pure UHMWPE (Nguyen.,2014). Similarly, blend of melamine-formaldehyde resin with low-density polyethylene (LDPE) had low friction value than that of neat LDPE (Brostow., 2008). Namdeo et al. (2016) investigated two-body abrasive wear behavior of ethylene-co-vinyl acetate (EVA) and high-density polyethylene (HDPE) polymer blend and found that $70 \mathrm{wt} \%$ of EVA and $30 \mathrm{wt} \%$ of HDPE had highest wear resistance.

Most polymer blends are immiscible and need to be compatibilized. Polymeric compatibilizers have the broadest range of opportunities in automotive, electrical/electronic, packaging, sports/recreation equipment, major appliance, and medical device applications. They can be used as blend compatibilizers, coupling agents, adhesion promoters and impact modifiers (Utracki.,2002). Namdeo et al. (2016) observed that the addition of 2 phr of maleic anhydride grafted polyethylene (MA-g-PE) lowered high-stress abrasive wear of EVA/HDPE polymer blend. Nanoparticles enhance the interaction with the other particles within the mixture, which are responsible for change in physical as well as chemical properties. These changes further led to the increase in the ratio of the surface area to volume and the size of the particle (Anandhan.,2011). It was also reported that MA-g-PE modified EVA/HDPE polymer blend had high adhesive two-body and three-body abrasive wear resistance with the addition of $4 \mathrm{phr}$ organ modified montmorillonite (OMMT) nano-clay (Namdeo.,2017).

Tribological parameters have been tailored in various ways. Surface treatment is an effective approach to modify wear and coefficient of friction. Irradiations of gamma-ray, x-ray, ultraviolet-ray, laser, etc. along with various surface treatments like rare earth, plasma, acid and many more have been used in the past to achieve desired surface properties. Irradiation with nanosecond laser pulses of ultraviolet and visible wavelengths on cross-linked hydrophilic co-polymeric materials showed that multiple-pulse irradiation at $266 \mathrm{~nm}$ with a limited number of laser shots can be used alternatively for generating a regular micro foam layer at the surface (Primo.,2016). A low-energy electron irradiation method was used to nanocrystalline the topsurface of amorphous carbon film in electron cyclotron resonance plasma system, which 
induced a lower friction than that of the original pure amorphous film because the electron irradiation gave rise to the formation of $\mathrm{sp}^{2}$ nano crystallites in the film top-surface within 4 nm thickness (Chen.,2016). Tiwari et al. used classical, as well as modern methods for surface treatment of carbon fabric in polyetherimide matrix to characterize the composites for interlaminar shear strength and adhesive wear. The treatments were with nitric acid $\left(\mathrm{HNO}_{3}\right)$ for different time intervals from 15 to 180 minutes and oxidation with concentrated $\mathrm{HNO}_{3}$ for various time intervals ranging from 30 to 180 minutes (Tiwari.,2011). Gamma irradiations with varying doses from 100-300 kilo-Gray to the twill weave carbon fiber have been reported (Tiwari.,2011). Cold remote nitrogen oxygen plasma treatment was also reported (Tiwari.,2011). Tiwari and Bijwe (2011) reported a comparative study of various methods used for surface treatment of carbon fiber and analyzed physical, chemical, and morphological changes occurred in fiber properties. These changes were due to treatment, which led to improved composite properties due to improved surface area on fiber surface, chemical bonding and adhesion between fiber and matrix.

Laser irradiation remains popular for surface modifications from metals to polymers, due to its controlled surface treatment ability with limited energy consumption. Flexibility and other benefits expanded application of laser irradiation surface treatment to space, medical, industrial and other applications. Plasmonic nanoparticles were inserted into the bulk of a transparent medium to modify the polymer matrix by laser light irradiation, which promoted alteration of the material properties (Smirnov.,2014). Macroscopic, microscopic and nanoscopic laser processed structures on aluminum and glass fiber reinforced thermoplastics joint of different fiber content increased high shear tensile strengths of up to $42 \mathrm{~N} / \mathrm{mm}^{2}$ (Heckert.,2014). Laser induced periodic surface structures (LIPSS) were induced on polyethylene terephthalate (PET) and polystyrene (PS) polymers substrates for formation of separated gold nanowires as well as alignment and activation of human cells (Barb.,2014). Laser-induced periodic surface structures increased coefficient of friction for structured areas (Eichstadt.,2011). Polymer matrix surfaces were also altered to modify surface properties. Laser material interaction with carbon fiber reinforced polymer (CFRP) has shown that the width of the working area is directly dependent on the beam diameter and not on number of passes. Also, higher removal rate can be achieved by increased total energy density instead of power density (Pagano.,2015). Proton irradiation of $25 \mathrm{keV}$ with influence of $2.25 \times 10^{17} \mathrm{ion} / \mathrm{cm}^{2}$ improved the main wear mechanism under three-body abrasion wear with low surface energy, which reduced the wear rate and the friction coefficient of polyimide blocks (Zheng.,2015). Thin single step irradiated 
and annealed ultra-high molecular weight polyethylene hip liners also exhibited an increase in both wear rate and volume loss (Negra.,2016). Surface modification effects by laser irradiation on allyl- Di glycol CR39 developed the photo thermal effect mechanism due to localized heat generation, which was responsible for surface structure modification (Zakaria.,2016). Femtosecond infrared laser irradiation enhanced carrier transport of poly (3-hexylthiophene): phenyl-C61-butyric acid methyl ester blend film by inducing a photo expansion without deteriorating molecular structure of polymer film (Chae.,2017). Low power laser irradiation improved the wear resistance of glass-fibre-reinforced polyester composites by enhancing cross linking in unsaturated polyester, modifying surface microstructure, and increasing the hardness of the composite material (Chand.,1996).

Development, moisture absorption, thermal and mechanical behavior of MA-g-PE modified EVA/HDPE nanocomposites were studied and reported (Rajan.,2011). Also, polymer EVA/HDPE/MA-g-PE/OMMT nanocomposite showed wear resistance characteristics in adhesive and abrasive wear modes (Namdeo.,2020). Laser irradiation is an effective way of modification of surfaces and bonding. Therefore, effects of laser irradiation on adhesive triboperformance of EVA/HDPE/MA-g-PE/OMMT (70/30/2/4) polymer nanocomposite have been investigated in this study.

\section{EXPERIMENTAL DETAILS}

\section{A. Laser irradiation and composition details}

Laser irradiations on composite specimens of sizes of $5 \times 5 \mathrm{~mm}^{2}$ cross sectional area were performed on Ytterbium Laser System (YSL-2000) Germany. The experimental parameters, such as, stand-off distance, wavelength and beam diameter for laser irradiation were kept as 15 $\mathrm{mm}, 1.08 \mu \mathrm{m}$ and $3 \mathrm{~mm}$ respectively. Untreated polymer nanocomposites were irradiated by laser at $2.69,3.123 .54$ and $3.97 \mathrm{~kW} / \mathrm{mm}^{2}$ power densities and $0.3,0.5$ and $0.7 \mathrm{~m} / \mathrm{min}$ scan speeds. Laser treatment of polymer nanocomposites used for adhesive tribo-performance along with their designations, hardness and densities has been presented in Table 1.

\section{B. Adhesive Test}

Coefficient of friction and specific wear rate observations in adhesive mode of polymer nanocomposites were evaluated. Experiments were conducted as per ASTM G99 standard using pin-on-disc apparatus [30]. Composite specimens of cross-sectional area of $5 \times 5 \mathrm{~mm}^{2}$ and $30 \mathrm{~mm}$ long held against rotating disc of steel EN31 of $165 \mathrm{~mm}$ diameter and $8 \mathrm{~mm}$ width. Surface roughness and hardness of rotating disc were $1.6 \mu \mathrm{m}$ and $60 \mathrm{HRC}$ respectively. The untreated and laser treated sample pins under test pressed at loads of 5, 10 and $15 \mathrm{~N}$ against 
rotating disc at $0.8 \mathrm{~m} / \mathrm{sec}$ sliding speed for 500, 700 and $900 \mathrm{~m}$ sliding distances. At least three samples for each set of influencing factors were tested. Specific wear rate was calculated using simple Archard's wear equation 1.

$$
\mathrm{K}_{\mathrm{s}}=\frac{\Delta V}{\mathrm{LxD}}
$$

Where, Ks is specific wear rate in $\mathrm{m}^{3} \mathrm{~N}^{-1} \mathrm{~m}^{-1} ; \Delta \mathrm{V}$ is volume loss in $\mathrm{m}^{3}$; L is Load in $\mathrm{N}$; and $\mathrm{D}$ is sliding distance in $\mathrm{m}$.

Table 1 Laser Treatment of Polymer Nanocomposites used for Adhesive Tribo-performance with their Designation, Hardness and Densities

\begin{tabular}{|c|c|c|c|c|}
\hline \multicolumn{2}{|c|}{$\begin{array}{c}\text { Laser Irradiation Variables } \\
\end{array}$} & \multirow{2}{*}{ Designation } & \multirow{2}{*}{$\begin{array}{l}\text { Hardness } \\
\text { (Shore A) }\end{array}$} & \multirow{2}{*}{$\begin{array}{l}\text { Density } \\
\left(\mathrm{Mg} \mathrm{m}^{-3}\right)\end{array}$} \\
\hline Scan Speed (m/min) & Power Density $\left(\mathrm{kW} / \mathrm{mm}^{2}\right)$ & & & \\
\hline & 2.69 & LT11 & 60.5 & 0.958 \\
\hline & 3.12 & LT12 & 58.0 & 0.952 \\
\hline & 3.54 & LT13 & 63.7 & 0.967 \\
\hline & 3.97 & LT14 & 61.8 & 0.962 \\
\hline & 2.69 & LT21 & 60.5 & 0.958 \\
\hline & 3.12 & LT22 & 58.0 & 0.952 \\
\hline & 3.54 & LT23 & 63.7 & 0.967 \\
\hline & 3.97 & LT24 & 61.8 & 0.962 \\
\hline & 2.69 & LT31 & 60.5 & 0.958 \\
\hline & 3.12 & LT32 & 58.0 & 0.952 \\
\hline & 3.54 & LT33 & 63.7 & 0.967 \\
\hline & 3.97 & LT34 & 61.8 & 0.962 \\
\hline Un-treated PNC & --- & UT & 61.5 & 0.961 \\
\hline
\end{tabular}

\section{RESULTS AND DISCUSSION}

Effects of load and sliding distance as well as the interaction effects of power density and scan speed with load on coefficient of friction and specific wear rate have been shown from Figures 1(a-b) to 4(a-b), respectively. Coefficient of friction display error bars for the chart series with $5 \%$ value and data labels were positioned at left side of data points by line charts, while bar charts were used to show specific wear rate display error bars for the chart series with $5 \%$ value and data labels positions outside the end of data points.

\section{A. Effect of load}

Effect of load on coefficient of friction and specific wear rate at $700 \mathrm{~m}$ sliding distance and 0.7 $\mathrm{m} / \mathrm{min}$ scan speed have been shown in Figures 1(a) and 1(b), respectively. It was observed that with the increment of load, coefficient of friction was decreased while specific wear rate was increased linearly with increment in load from $5 \mathrm{~N}$ to $15 \mathrm{~N}$. Coefficient of friction was increased from LT31 to maximum for LT32, then lowest for LT33 and again increased slightly for LT34 and UT at all loads. The highest and lowest coefficients of friction were observed as 
0.55 at $5 \mathrm{~N}$ load for LT32 and 0.41 at $15 \mathrm{~N}$ load for LT33. Specific wear rate was found in order of LT33<LT34<LT31<UT<LT32 at $5 \mathrm{~N}$ load and LT33<LT34<UT<LT31<LT32 for 10 $\mathrm{N}$ and $15 \mathrm{~N}$ loads. Minimum specific wear rate 4.304x10-15 $\mathrm{m}^{3} \mathrm{~N}^{-1} \mathrm{~m}^{-1}$ at $5 \mathrm{~N}$ load for LT33 and maximum specific wear rate $83.664 \times 10^{-15} \mathrm{~m}^{3} \mathrm{~N}^{-1} \mathrm{~m}^{-1}$ at $15 \mathrm{~N}$ for LT21 were recorded.

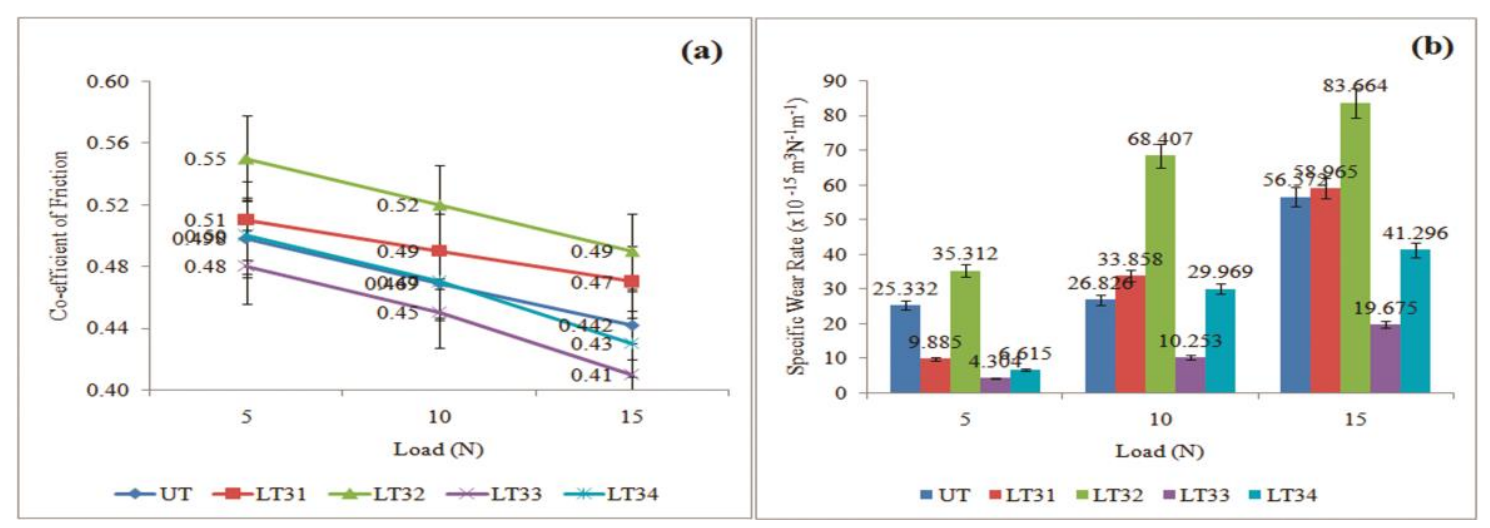

Figure 1 Effect of load on (a) coefficient of friction and (b) specific wear rate at $700 \mathrm{~m}$ sliding distance and $0.7 \mathrm{~m} / \mathrm{min}$ scan speed

\section{B. Effect of sliding distance}

Effect of sliding distance at $10 \mathrm{~N}$ load and $0.7 \mathrm{~m} / \mathrm{min}$ scan speed on coefficient of friction and specific wear rate have been displayed in Figures 2(a) and 2(b), respectively. It was observed that sliding distance did not affect coefficient of friction and it remained almost constant. However, it was found in order of LT33<LT34<UT< LT31<LT32. Minimum and maximum coefficients of friction were found as 0.446 for LT33 at $500 \mathrm{~m}$ and 0.52 for LT32 at $900 \mathrm{~m}$ sliding distances. On the contrary, specific wear rate was decreased with increment in sliding distance. LT31 and LT32 exhibited higher specific wear rate than untreated polymer nanocomposite (UT), while LT33 and LT34 had lower specific wear rate than UT. LT33 had the least wear among all treated PNC. Least specific wear rate of $8.976 \times 10^{-15} \mathrm{~m}^{3} \mathrm{~N}^{-1} \mathrm{~m}^{-1}$ observed at $900 \mathrm{~m}$ sliding distance for LT33, while LT32 had the most specific wear rate of $72.68 \times 10^{-15} \mathrm{~m}^{3} \mathrm{~N}^{-1} \mathrm{~m}^{-1}$ at $500 \mathrm{~m}$ sliding distance.

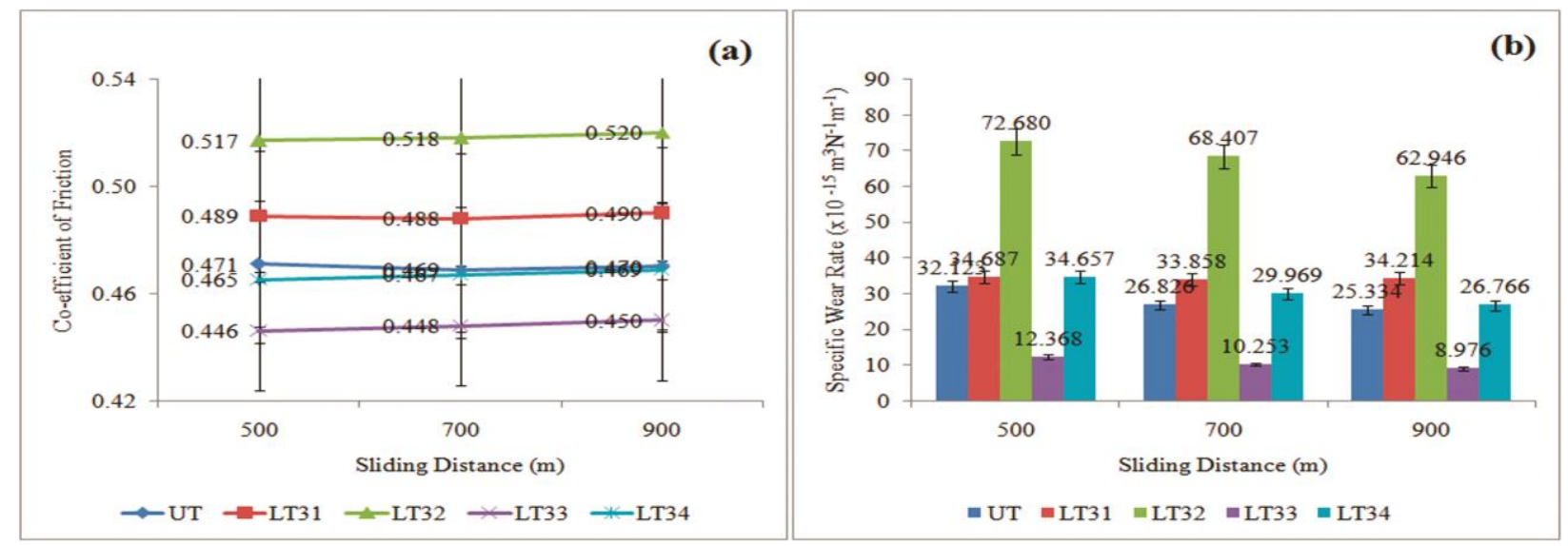


Figure 2 Effect of sliding distance on (a) coefficient of friction and (b) specific wear rate at 10 $\mathrm{N}$ load and $0.7 \mathrm{~m} / \mathrm{min}$ scan speed

\section{Interaction effects of power density and load}

Interaction effects of power density and load on coefficient of friction and specific wear rate at $700 \mathrm{~m}$ sliding distance and $0.7 \mathrm{~m} / \mathrm{min}$ scan speed have been shown in Figures 3(a) and 3(b), respectively. Both coefficient of friction and specific wear rate were increased from 2.69 $\mathrm{kW} / \mathrm{mm}^{2}$ power density to the highest at $3.12 \mathrm{~kW} / \mathrm{mm}^{2}$ then decreased to the lowest for 3.54 $\mathrm{kW} / \mathrm{mm}^{2}$ and again increased marginally to $3.97 \mathrm{~kW} / \mathrm{mm}^{2}$ at all loads. It was observed that coefficient of friction was decreasing from $5 \mathrm{~N}$ load to $10 \mathrm{~N}$ load and then sharply to $15 \mathrm{~N}$ load, while specific wear rate was increasing with load at constant rate from $5 \mathrm{~N}$ load to $10 \mathrm{~N}$ load and then to $15 \mathrm{~N}$ load. Coefficient of friction had the lowest value of 0.41 at $3.54 \mathrm{~kW} / \mathrm{mm}^{2}$ power density for $15 \mathrm{~N}$ load and the highest value of 0.55 at $3.12 \mathrm{~kW} / \mathrm{mm}^{2}$ power density for 5 $\mathrm{N}$ load. Minimum and maximum specific wear rates were observed as $4.104 \times 10^{-15} \mathrm{~m}^{3} \mathrm{~N}^{-1} \mathrm{~m}^{-1}$ at $5 \mathrm{~N}$ load for $3.54 \mathrm{~kW} / \mathrm{mm}^{2}$ power density and $83.664 \times 10^{-15} \mathrm{~m}^{3} \mathrm{~N}^{-1} \mathrm{~m}^{-1}$ at $15 \mathrm{~N}$ load for 3.12 $\mathrm{kW} / \mathrm{mm}^{2}$ power density.

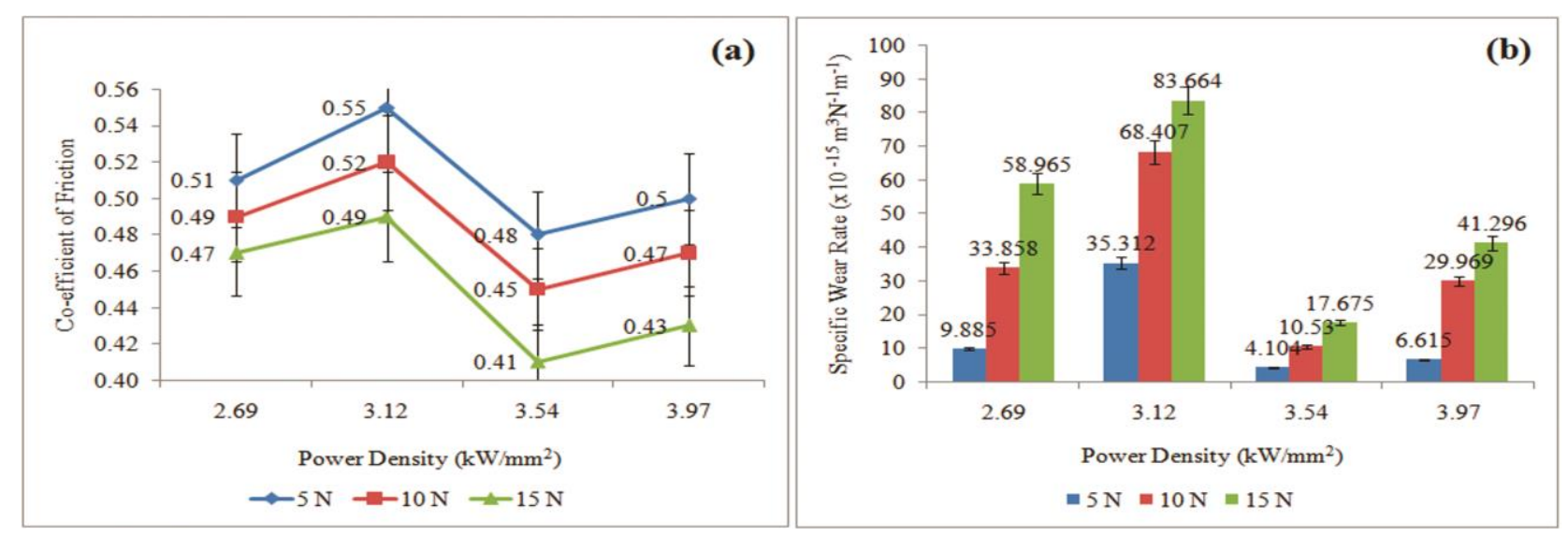

Figure 3 Interaction effects of power density and load on (a) coefficient of friction and (b) specific wear rate at $700 \mathrm{~m}$ sliding distance and $0.7 \mathrm{~m} / \mathrm{min}$ scan speed

\section{Interaction effects of scan speed and load}

Interaction effects of scan speed and load on ccoefficient of friction and specific wear rate at $3.54 \mathrm{~kW} / \mathrm{mm}^{2}$ power density and $700 \mathrm{~m}$ sliding distance have been displayed in Figures 4(a) and 4(b), respectively. It was observed that coefficient of friction was increased slightly from $0.3 \mathrm{~m} / \mathrm{min}$ scan speed to $0.5 \mathrm{~m} / \mathrm{min}$ scan speed and further marginally down to $0.7 \mathrm{~m} / \mathrm{min}$ scan speed. It was decreasing with increment of load from $5 \mathrm{~N}$ to $15 \mathrm{~N}$. Maximum and minimum coefficients of friction were found as 0.53 at $5 \mathrm{~N}$ load for $0.5 \mathrm{~m} / \mathrm{min}$ scan speed and 0.41 at 15 
$\mathrm{N}$ load for $0.7 \mathrm{~m} / \mathrm{min}$ scan speed, respectively. On the other hand, specific wear rate was affected slightly with scan speed at all applied loads but increased with increment in loads. The lowest $4.104 \times 10^{-15} \mathrm{~m}^{3} \mathrm{~N}^{-1} \mathrm{~m}^{-1}$ and the highest $18.299 \times 10^{-15} \mathrm{~m}^{3} \mathrm{~N}^{-1} \mathrm{~m}^{-1}$ specific wear rates were found at $0.7 \mathrm{~m} / \mathrm{min}$ scan speed for $5 \mathrm{~N}$ load and $0.5 \mathrm{~m} / \mathrm{min}$ scan speed for $15 \mathrm{~N}$ load.

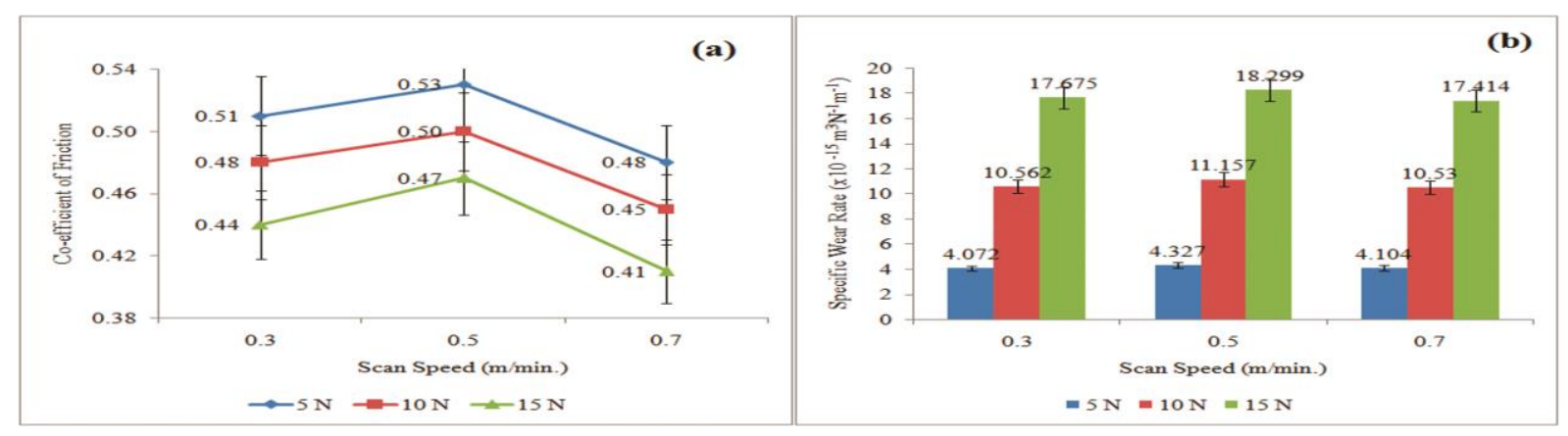

Figure 4 Interaction effects of scan speed and load on (a) coefficient of friction and (b)specific wear rate at $3.54 \mathrm{~kW} / \mathrm{mm}^{2}$ power density and $700 \mathrm{~m}$ sliding distance

It was observed that coefficient of friction was varied with load and power density. It remained almost constant with sliding distance and decreased with increase in load due to visco-elastic behavior of polymer nanocomposites. Power density affected coefficient of friction in a variable manner. Initially it increased and then reduced drastically and further became steady. It was observed that, laser irradiation at 2.69 and $3.12 \mathrm{~kW} / \mathrm{mm}^{2}$ reduced hardness, while further increase in power density (at $3.97 \mathrm{~kW} / \mathrm{mm}^{2}$ ) increased hardness. Therefore, specific wear rate increased first and then decreased. Scan speed had marginal variation in coefficient of friction. Similar findings for the effect of load and distance on coefficient of friction have also been reported by Zuo et al. (2011), Wang et al. (2013) and Chen et al. (2014).

Laser irradiation causes phase transformation of the polymer nanocomposites due to local heat zone produced during laser irradiation. This phase transformation is associated with the process of diffusion-controlled dislocation hardening mechanism which is taking place in the localized region. The accepted concept is that these dislocations became mobile and localized through diffusion having some jump frequency when the applied tensile stress is less than the yield stress. This gave rise to the change in fracture toughness and hardness value of the composites. Therefore, specific wear rate was increased with increase in load and power density, while decreased with increase in sliding distance in all cases. The present results agree with those of Dayma et al. (2011) and Suresha et al. (2012).

\section{E. Scanning electron microscopic (SEM) analysis}

Adhesive wear in a polymer-metal sliding system resulted due to interactions between polymer molecules and metal atoms at the sliding interface. Dissipation of frictional energy at the 
sliding interface increased the molecular mobility, produced thermal softening, or even caused degradation of the polymeric material in extreme cases [37]. Mainly adhesive wear process of polymer-metal interaction involves initial contact of the polymer and metal surface. Subsequently deformable polymer molecules were gradually transferred to the hard counter face in running-in process. Finally, wear is influenced by shear and adhesive property of the transferred film .

Scanning electron microscope (Carl Zeiss Sigma - Gemini) was used to examine thin silverplated worn surfaces of samples. SEM images of untreated and laser treated polymer nanocomposites UT PNC, LT31, LT32, LT33 and LT34 at $10 \mathrm{~N}$ load, $700 \mathrm{~m}$ sliding distance and $0.8 \mathrm{~m} / \mathrm{s}$ sliding velocity have been shown in Figures 5(a)-5(e) respectively.
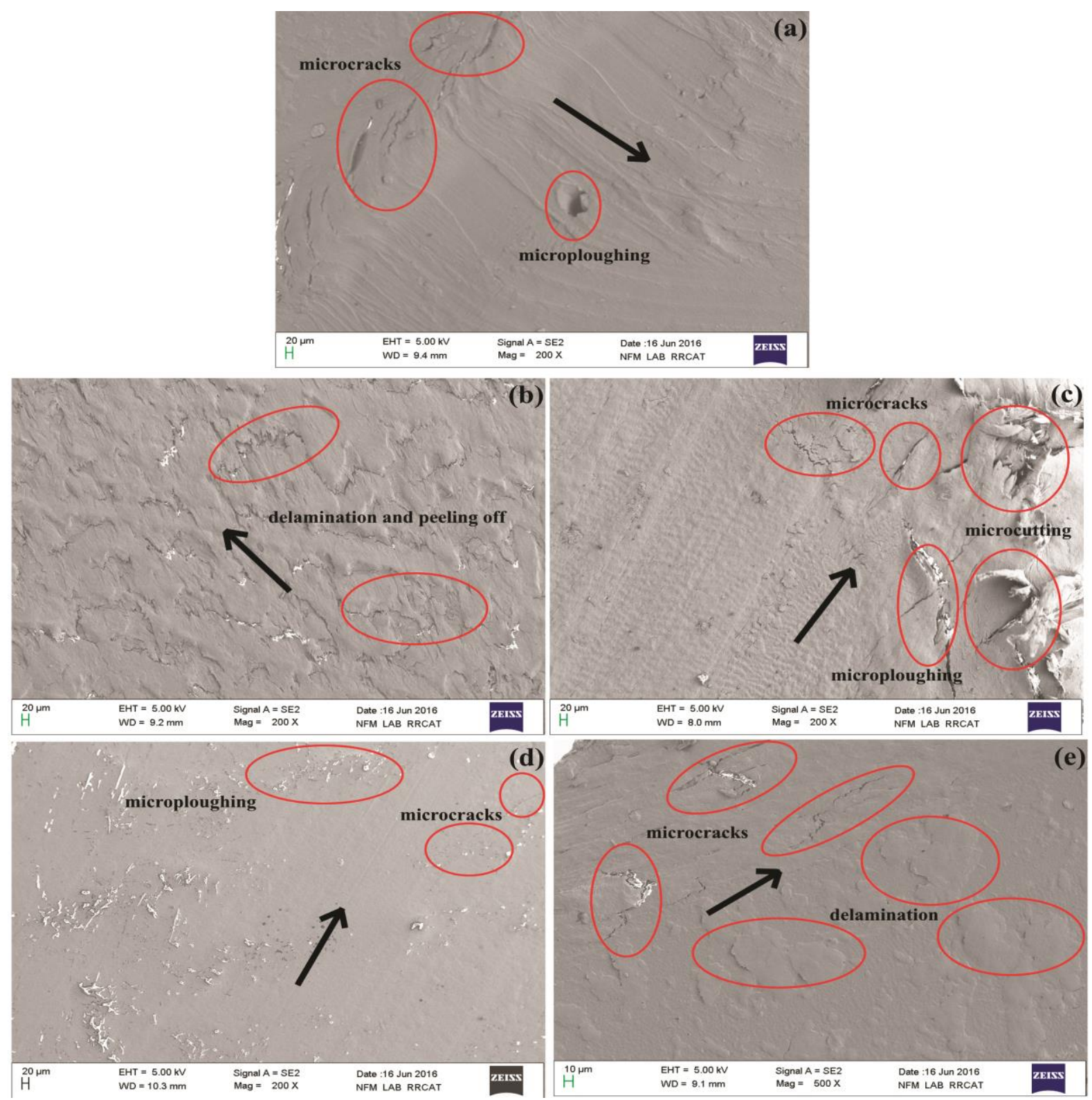
Figure 5 Scanning electron microscopic images of polymer nanocomposites in adhesive wear at $10 \mathrm{~N}$ load, $700 \mathrm{~m}$ sliding distance and $0.8 \mathrm{~ms}^{-1}$ sliding velocity (a) UT PNC, (b) LT31, (c)

$$
\text { LT32, (d) LT33 and (e) LT34 }
$$

Directions of sliding were shown by arrows, while oval marks showed remarkable damage of surfaces. Micro ploughing and microcracking wear mechanisms of surface matrix were observed in Figure 5(a), while delamination and peeling off of worn surface exhibited blisters on surface as shown in Figure 5(b). At $3.12 \mathrm{~kW} / \mathrm{mm}^{2}$ power density, thermal softening of rubbing surfaces caused flow of matrix in the direction of sliding, which was seen by severe microcracking, micro ploughing and micro cutting in Figure 5(c). Subsequent increased in power density to $3.54 \mathrm{~kW} / \mathrm{mm}^{2}$ improved hardness of surface and therefore minor adhesive rubbing marks with microcracking and micro ploughing were appeared in Figure 5(d). Further, increase in power density was responsible for subsequent deterioration of surface with microcracking and delamination as shown in Figure 5(e). These findings corroborate with that of Briscoe and Sinha (2014) and Martinez et al. (2015).

Laser irradiation involves rapid heating and cooling of local region due to increase in mobility of energy by the excited molecules brought changes in the chemical and microstructural features of the surfaces. A dynamic temperature region is produced, which helps in simulating the cross-linking processes at the localized region. This modification was further characterized by increased surface energy. This decreases the magnitude of failure at the surface and hence improves the wear resistance of LT33 and LT34 in comparison to UT PNC, LT31 and LT32. These wear mechanisms reveal that the wear mechanism of the laser irradiated nanocomposites may be altered by changes in the polymer matrix and the interfacial bonding.

\section{CONCLUSION}

Effects of laser irradiation on adhesive tribo-performance of EVA/HDPE/MA-g-PE/OMMT (70/30/2/4) polymer nanocomposite were investigated in this work. Outcomes of this experimental study are as follows:

- Coefficient of friction was independent to sliding distance, while decreased with increase in load.

- Specific wear rate was decreased with increase in sliding distance. On the other hand, it was increased with increase in load.

- Coefficient of friction and specific wear rate were highly affected by power density, while remained almost constant with scan speed. 
- Laser irradiated polymer nanocomposite at $3.54 \mathrm{~kW} / \mathrm{mm}^{2}$ power density and $0.7 \mathrm{~m} / \mathrm{min}$ scan speed, i.e., LT33 had least coefficient of friction and specific wear rate for all applied loads and sliding distances.

- SEM images were explained wear mechanism of worn surfaces and shown that polymer nanocomposite irradiated at power density $3.54 \mathrm{~kW} / \mathrm{mm}^{2}$ is subjected to least wear.

\section{ACKNOWLEDGEMENT}

Authors would like to the acknowledge scientists and staffs of Raja Ramanna Centre for Advanced Technology, Indore, Madhya Pradesh, India for their valuable and unconditional support during this experimental research work.

\section{REFERENCES}

Anandhan, S. \& Bandyopadhyay, S. 2011. Polymer Nanocomposites: From Synthesis to Applications, Nanocomposites and Polymers with Analytical Methods. In: Cuppoletti J. (ed.) DOI: 10.5772/17039

ASTM G99-04, 2004. Standard Test Method for Wear Testing with a Pin-on-Disk Apparatus. ASTM International, West Conshohocken, PA.

Barb, R. A., Hrelescu, C., Dong, L., Heitz, J., Siegel, J., Slepicka, P., Vosmanska, V., Svorcik, V., Magnus, B., Marksteiner, R., Schernthaner, M. \& Groschner, K. 2014. Laser-induced periodic surface structures on polymers for formation of gold nanowires and activation of human cells. Appl. Phys. A 117: 295-300. DOI: 10.1016/j.phpro.2011.03.099.

Briscoe, B. J. \& Sinha, S. K. 2002. Wear of polymers, Proceedings of the Institution of Mechanical Engineers. Part J: Journal of Engineering Tribology. 216 (6): 401-413. DOI: $10.1243 / 135065002762355325$.

Brostow, W., Datashvili, T. \& Huang, B. 2008. Tribological Properties of Blends of Melamine-Formaldehyde Resin with Low Density Polyethylene. Polym Eng Sci. 48 (2): 292-296. DOI: 10.1002/pen.20898.

Chae, S., Yi, A., Park, C., Chang, W. S., Lee, H. H., Choi, J. \& Kim, H. J. 2017. Using Femtosecond Laser Irradiation to Enhance the Vertical Electrical Properties and Tailor the Morphology of a Conducting Polymer Blend Film. ACS Appl. Mater. Interfaces. 9 (29): 24422-24427. DOI: 10.1021/acsami.7b05937.

Chand, N. \& Fahim, M. 1996. Effect of laser irradiation on abrasive wear of glass fibre polyester composite. Tribol Lett. 2(1): 81-87. DOI: 10.1007/BF00182550. 
Chand, N. \& Gomit, S. 2000. An approach to three-body abrasive wear behaviour of laser irradiated short glass fibre polyester composites. In: Mathur, G. N., Kandpal, L. D. \& Sen, A. K. Proceedings of Recent Advances in Polymers and Composites (ed): 534-539.

Chen, C., Fan, X. \& Diao, D. 2016. Low-energy electron irradiation induced top-surface nano crystallization of amorphous carbon film. Appl Surf Sci. 384: 341-347. DOI: 10.1016/j.apsusc.2016.05.042.

Chen, J., Guo, Q., Zhang, S., Wang, X. \& Shao, X. 2012. Research on Friction and Wear Behaviors of PEEK/PEI/PES Plastics Alloys under Sliding Contact Condition. Procedia Engineer. 36: 285-291. DOI: 10.1016/j.proeng.2012.03.042.

Dayma, N., Satapathy, B. K. \& Patnaik, A. 2011. Structural correlations to sliding wear performance of PA-6/PP-g-MA/nanoclay ternary nanocomposites. Wear. 271 (5-6): 827836. DOI: 10.1016/j.wear.2014.03.002.

Eichstadt, J., Romer, G. R. B. E. \& VeldJ Huisin't, A. J. 2011. Towards Friction Control using laser-induced periodic Surface Structures. LiM Physcs Proc. 12 (B): 7-15. DOI: 10.1016/j.phpro.2011.03.099.

Heckert, A. \& Zaeh, M. F. 2014. Laser Surface Pre-treatment of Aluminum for Hybrid Joints with Glass Fibre Reinforced Thermoplastics. VIII International Conference on Photonic Technologies, Physcs Proc. 56: 1171-1181. DOI: 10.1016/j.phpro.2014.08.032.

Kar, M. K. 1978. Micro mechanism of wear at polymer-metal sliding interface. Retrospective Thesis and Dissertation. http://lib.dr.iastate.edu/rtd/6499.

Lv, M., Zheng, F., Wang, Q., Wang, T. \& Liang, Y.2015. Effect of proton irradiation on the friction and wear properties of polyimide. Wear, 316: 30-36. DOI: 10.1016/j.wear.2014.04.011.

Martinez, F. J., Canales, M., Bielsa, J. M. \& Jime nez, M. A. 2009. Relationship between wear rate and mechanical fatigue in sliding TPU-metal contacts. Wear. 268: 388-398. DOI: 10.1016/j.wear.2009.08.026.

Namdeo, R., Tiwari, S. \& Manepatil, S. 2017. Optimi zation of High Stress Abrasive Wear of Polymer Blend Ethylene and Vinyl Acetate Copolymer/HDPE/MA-g-PE/OMMT Nanocomposites. Transactions of the ASME Journal of Tribology. 139: 021610-1-6. DOI: $10.1115 / 1.4034696$.

Namdeo, R., Tiwari, S., Manepatil, S. \& Chand, N. 2016. Optimizing the Effect of Addition of MA-g-PE Compatibilizer on Two-body Abrasive Wear Behavior of EVA/HDPE Polymer blend using Taguchi and ANOVA. ELK Asia Pacific Journals Special Issue International conference on ARIMPIE: 39-43. ISBN: 978-81-930411-8-5. 
Namdeo, R., Tiwari, S., Manepatil, S. \& Chand, N. 2016. Two-body Abrasive Wear Behaviors of Polyethylene vinyl acetate copolymer/High-density Polyethylene (EVA/HDPE) Polymer Blends. National Conference on Emanate Trends in Mechanical \& Allied Engineering Sciences: 1-7. ISBN: 978-81-925456-3-9.

Namdeo, R., Tiwari, S., Manepatil, S. \& Chand, N. 2018. Effect of Addition of Organ modified Montmorillonite Nano clay on Three-Body Abrasive Wear Behavior of Maleic Anhydride Grafted Polyethylene Compatibilized Ethylene-co-Vinyl Acetate/High Density Polyethylene Nanocomposites. Polym Composite. 39 (11): 3962-3968. DOI: $10.1002 / p c .24438$.

Namdeo, R., Tiwari, S., Manepatil, S. \& Chand, N. 2020. Experimental Analysis of Dry Sliding Friction and Wear Behavior of OMMT Nanoclay Added EVA/HDPE/MA-g-PE Compatibilized Polymer Blends with Parametric Study of Influencing Factors. Journal of Testing and Evaluation. 48 (2): 1122-1137. DOI: 10.1520/JTE20170611.

Nguyen, X. T., Panin, S. V., Kornienko, L. A., Ivanova, L. P., Korchagin, M. A. \& Shilko, S. V. 2014. Mechanical and tribotechnical properties of polymer-polymeric composites based on UHMWPE-PTFE blends. Mechanical Engineering Automation and Control Systems: 1-7. DOI: 10.1109/MEACS.2014.6986939.

Pagano, N., Ascari, A., Liverani, E., Donati, L., Campana, G. \& Fortunato, A. 2015. Laser interaction with Carbon Fibre Reinforced Polymers. IX CIRP Conference on Intelligent Computation in Manufacturing Engineering Procedia CIRP. 33: 423-427. DOI: 10.1016/j.procir.2015.06.097.

Primo, G. A., Alvarez, I. C. I., Pino, G. A., Ferrero, J. C. \& Rossa, M. 2016. Surface morphological modification of crosslinked hydrophilic co-polymers by nanosecond pulsed laser irradiation. Appl Surf Sci. 369: 422-429. DOI: 10.1016/j.apsusc.2016.02.047.

Puppulin, L. Negra, S. D., Sugano, N., Sbaizero, O. \& Pezzott, G. 2016. Surface modifications induced by in-vitro wear and oxidation on $\gamma$-irradiated UHMWPE hip liners belonging to different commercial generations. J Mech Behav Biomed. 53: 414426. DOI: 10.1016/j.jmbbm.2015.08.035.

Rajan, A. 2011. Development of MA-g-PE modified EVA/HDPE nanocomposites and their mechanical, thermal and moisture absorption behaviour. Dissertation, Gautam Buddh Technical University, Lucknow, India.

Robeson, L. M. 1984. Application of Polymer Blends: Emphasis on Recent Advances. Polym Eng Sci, 24 (8): 587-597. DOI: 10.1002/pen.760240810. 
Smirnov, A. A., Pikulin, A., Sapogova, N. \& Bityurin, N. 2014. Femtosecond Laser Irradiation of Plasmonic Nanoparticles in Polymer Matrix: Implications for Photothermal and Photochemical Material Alteration. Micromachines. 5 (4): 1202-1218. DOI: $10.3390 / \mathrm{mi} 5041202$.

Suresha, B., Siddaramaiah, K., Seetharamu, S. \& Kumaran, P. S. 2009. Investigations on the influence of graphite filler on dry sliding wear and abrasive wear behaviour of carbon fabric reinforced epoxy composites. Wear. 267: 1405-1414. DOI: 10.1016/j.wear.2009.01.026.

Tiwari, S. \& Bijwe, J. 2014. Surface Treatment of Carbon Fibers - A Review. Proc Tech. 14: 505-512. DOI: 10.1016/j.protcy.2014.08.064.

Tiwari, S., Bijwe, J. \& Panier, S. 2011. Adhesive wear performance of polyetherimide composites with plasma treated carbon fabric. Tribol Int. 44 (7-8): 782-788. DOI: 10.1016/j.triboint.2011.01.009.

Tiwari, S., Bijwe, J. \& Panier, S. 2011. Gamma radiation treatment of carbon fabric to improve the fiber-matrix adhesion and tribo-performance of composites. Wear. 271 (910): 2184-2192. DOI: 10.1016/j.wear.2010.11.032.

Tiwari, S., Bijwe, J. \& Panier, S. 2011. Polyetherimide composites with gamma irradiated carbon fabric: Studies on abrasive wear. Wear. 270 (9-10): 688-694. DOI: 10.1016/j.wear.2011.01.035.

Tiwari, S., Bijwe, J. \& Panier, S. 2011. Tribological studies on polyetherimide composites based on carbon fabric with optimized oxidation treatment. Wear. 271 (9-10): 22522260. DOI: 10.1016/j.wear.2010.11.052.

Tiwari, S., Bijwe, J. \& Panier, S. 2012. Optimization of surface treatment to enhance fibermatrix interface and performance of composites. Wear. 274-275: 326-334. DOI: 10.1016/j.wear.2011.09.014.

Utracki, L. A. 2002. Compatibilization of Polymer Blends. Can. J. Chem. Eng. 80 (6): 10081016. DOI: $10.1002 /$ cjce.5450800601.

Wang, S., Li, Q., Zhang, S. \& Pan, L. 2013. Tribological behavior of poly (phenyl phydroxybenzoate)/ polytetrafluoroethylene composites filled with hexagonal boron nitride under dry sliding condition. Mater Design. 43: 507-512. DOI: 10.1016/j.matdes.2012.07.048.

Zakaria, R. 2016. Surface Modification of Polymer Materials Induced by Laser Irradiation. In: D. Yang (eds.) Applications of Laser Ablation - Thin Film Deposition, Nanomaterial Synthesis and Surface Modificatio. 16. DOI: 10.5772/66377. 
Zuo, Z., Song, L. \& Yang, Y. 2015. Tribological behavior of polyethersulfone-reinforced polytetrafluoroethylene composite under dry sliding condition. Tribol Int. 86: 17-27. DOI: 10.1016/j.triboint.2015.01.019. 